\title{
EL HÉROE EN LA POESÍA DIDÁCTICA DE VIERA Y CLAVIJO
}

Es fácil desacreditar una obra literaria por el simple hecho de no entenderla. Y es lo que en cierto modo ha ocurrido con la poesía didáctica de José de Viera y Clavijo (1731-1813), la cual es poco o nada comprensible en la órbita de la literatura española del siglo XVIII. Así, no extraña que se tilde alegremente a Los aires fijos (1780) de "largo e insufrible poema"l y al tema cantado ahí -el de los gases o aires fijos recién descubiertos- de "árido e incongruente" 2 . Se olvida o se desconoce que a Viera le interesa enseñar, por encima de todo, por medio de esas obras. Pero la seriedad del asunto no le impide tomárselo con humor, a veces en clave de chufla conceptista, cuando describe sus experimentos químicos, transmite teorías científicas o se entromete en el relato para acreditar con su propia experiencia la veracidad de lo afirmado. ¿Por qué calificarlo de insufrible o de árido?, me pregunto. La poesía neoclásica resulta a veces, más de lo que en principio pudiera sospecharse, bastante densa y hasta complicada de entender. No es tan ligera y prosaica como algunos críticos suponen. Convengo, sí, en que la musa didascálica no es la más atractiva de la fiesta, pero a veces infunde "gracias y energía / al desmayo didáctico", como con tímida resolución apostillaba Viera. Sólo que a esta Cenicienta desmaquillada la ha de cortejar un príncipe leído que sepa apreciar sus ocultos encantos y entender el secreto de su pálida y trascendental belleza.

Porque esta clase de poesía, que "d'un style simple et vrai fait parler la raison" -en el atinado decir del abate Jacques Delille ${ }^{3}-$, p. 101.

1 Juan A. Ríos, “Dos «abates empolvorados» en París”, Canelobre, 16 (1989),

${ }^{2}$ Enrique Romeu Palazuelos, Biografía de Viera y Clavijo a través de sus obras, Aula de Cultura de Tenerife, Santa Cruz, 1981, p. 73.

${ }^{3}$ L'imagination, poème, Giguet et Michaud, Paris, 1806, t. 1, p. 1. 
no puede valorarse desde el prisma, deformado por lo anacrónico, de la crítica estética de base impresionista. Pero además la poesía didáctica de Viera ha de ponerse en relación con las corrientes europeas contemporáneas -en especial con la poesía descriptiva de un Delille o de un Saint-Lambert- y, en general, con la literatura y cultura francesas de los años anteriores a la Revolución. Sólo así podrá comprenderse en su justa medida ${ }^{4}$.

No pretendo entrar ahora en matizaciones sobre las diferencias extensivas o intencionales de poemas como Los meses (1796 $)^{5}$, en doce cantos, "imitando al de Mr. Roucher, pero original por la mayor parte" 6 , o Las bodas de las plantas (1806) ${ }^{7}$, en un solo canto y octavas reales, aunque de uno y otro habré de valerme para mi propósito. Lo que me interesa ahora es poner de relieve, en la práctica poética de Viera, la transformación sufrida en el lenguaje y en la tópica proemial de esas composiciones, que asumen en el siglo ilustrado la tradición evolutiva que se inaugura en la épica grecolatina y se desarrolla a lo largo del Siglo de Oro bajo la forma readaptada a las nuevas circunstancias de la épica culta ${ }^{8}$. La poesía didáctica del nuevo clasicismo exalta las Nobles Artes ${ }^{9}$ y la nueva ciencia experimental ${ }^{10}$. La invención original consistirá, en palabras de Chénier, en forjar versos antiguos, es decir, neoclásicos, "sur des pensers nouveaux". Éstos son los que los philosophes -ya sean pensadores especulativos o activos hombres de cienciahan revelado a la humanidad y el poeta busca en el sistema de Newton, Locke, Montesquieu, Voltaire, Buffon, Nollet, Helvétius o Condillac. En ese sentido es importante el enriquecimiento

4 Alejandro Cioranescu, "Viera y Clavijo y la cultura francesa", en Estudios de literatura española y comparada, Universidad, La Laguna, 1954, pp. 207-248.

${ }^{5}$ Los meses. Poema por don José de Viera y Clavijo. Obra inédita, Imprenta Isleña, Santa Cruz, 1849.

${ }^{6}$ Memorias que con relación a su vida literaria escribió D. José de Viera y Clavijo, que he de citar por José de Viera y Clavijo, Diccionario de historia natural de las islas Canarias, ed. Manuel Alvar, $3^{\text {a }}$ ed., Cabildos Insulares, Madrid-Las Palmas, 1982, p. lxxxvii.

${ }^{7}$ Las bodas de las plantas. Obra póstuma de D. José de Viera y Clavijo, ed. J. Teixidó y Cos, Federico Martí y Cantó, Barcelona, 1873.

8 Antonio Prieto, "Origen y transformación de la épica culta en castellano", Coherencia y relevancia textual. De Berceo a Baroja, Alhambra, Madrid, 1980, pp. 117178.

9 José Cebrián, "Poesía didáctica y Nobles Artes en la Ilustración española”, Dieciocho, 19 (1996), 73-99.

10 José Cebrián, "Poesía didáctica y ciencia experimental en la Ilustración española”, BHi, 98 (1996), 121-135. 
experimentado en el léxico poético con la incorporación de los nombres propios de esos "nuevos Plinios", elevados a la condición de héroes épicos, así como de los neologismos y tecnicismos surgidos a raíz de los saberes auspiciados por el Siglo de las Luces. "Si l'imagination est belle en poésie, la raison en vers est admirable", escribirá Chênedollé en Le génie de l’homme (1807) ${ }^{11}$.

Sin embargo, la poesía didáctica del siglo xviII no rompe con el lenguaje tradicional de la épica culta ni renuncia a las alusiones mitológicas, al codificado ritual del exordio o a la presencia de alegorías $^{12}$, recursos todos ellos caros a la narrativa en verso de cuño clasicista, aunque omite, por ser ya anacrónico, el apóstrofe o dedicatoria en clave de captatio benevolentice a "personajes poderosos que aún viven"13.

Interesa recordar que Viera y Clavijo ya había ensayado el esquema miniaturizado del canto épico -breve, autónomo, condensado, de entre cincuenta y un centenar largo de octavas ${ }^{14}$ - en Los vasconautas (1766) ${ }^{15}$, "pequeño poema épico" en clave humorística, subdividido a la vez en cuatro cantos en miniatura, donde -recalca con guasa muy suya- "brillan todas las grandes perfecciones de la epopeya y retozan las mejores gracias del heroísmo". E importa porque es el organigrama compositivo que repetirá, años más tarde, en Los aires fijos con similar dosis de "bellezas poéticas, muchas para un campo tan reducido" 16 .

Al igual que Saint-Lambert -que había dado comienzo a Les saisons (1769) proponiéndose cantar "les saisons et la marche féconde / de l'astre bienfaisant qui les dispense au monde" 17 , en

${ }^{11}$ Que citaré por CEuvres complètes de Charles Chênedollé, Firmin Didot, Paris, 1864, p. xxviii.

12 Michael Nerlich, Untersuschungen zur Theorie des klassizistischen Epos in Spanien (1700-1850), Droz/Minard, Genève-Paris, 1964, pp. 187-206.

13 Santos Díez González, Instituciones poéticas, con un discurso preliminar en defensa de la poesía, Benito Cano, Madrid, 1793, p. 62. Pero la idea de que "la dedicación no es parte necesaria y puede omitirse al arbitrio del poeta" está ya en $L a$ poética o reglas de la poesía en general y de sus especies principales (1737) de LuzÁN (p. 604. Las citas irán por la edición de Russell P. Sebold, Labor, Barcelona, 1977).

${ }^{14}$ Frank Pierce, "The canto épico of the Seventeenth and Eighteenth centuries", $H R, 15$ (1947), 1-48; José Cebrián, "El género épico en España: de los poemas mayores al canto épico”, Philologia Hispalensis, 4 (1989), 171-183.

${ }^{15}$ Ed. Miguel Pérez Corrales, Universidad, La Laguna, 1983.

${ }^{16}$ Discurso de la poesía épica antepuesto a Los vasconautas, pp. 17-18.

17 Les saisons, poème, 7ème éd., Amsterdam, 1775, p. 39. Véase Luigi de NARDIS, Saint-Lambert. Scienza e paesaggio nella poesia del Settecento, Ateneo, Roma, 1961, en esp. pp. 121-142. 
remedo de la fórmula proemial de primera persona consagrada por Virgilio-18, nuestro abate inicia Los aires fijos declarando con la brevedad, modestia y claridad exigida ${ }^{19}$ su objeto: enaltecer "los aires que en calcaria tierra, / en marcial polvo, rojo azogue y minio / la forma fija y la materia encierra”. ¿Con claridad? Sólo en apariencia, pues el lector debía saber de antemano el significado conceptual de los sintagmas enumerados: que calcaria tierra era cualquier roca caliza, marcial polvo, pirita de hierro y rojo azogue y minio óxidos de mercurio y plomo respectivamente. Suficiente para que el librito se le cayese de las manos, a no ser que fuera un entusiasta de los adelantamientos de las ciencias empíricas.

Sin embargo, las dificultades de comprensión de Los aires fijos no debieron de ser tan engorrosas para sus primeros y genuinos destinatarios: las "muchas personas condecoradas, damas de la grandeza, algunos médicos y boticarios, profesores de física y otros sujetos amantes de las ciencias" 20 que presenciaron los experimentos químicos realizados por Viera -"el primero que demostró en esta corte los fenómenos principales de los gases"- en un pequeño curso sobre aires fijos dictado en el gabinete de física del Marqués de Santa Cruz tras la vuelta de su viaje a Francia y Flandes en 1779. En realidad, no hizo otra cosa que repetir lo que había aprendido en París de las demostraciones de Joseph-Aignan Sigaud de Lafond (1730-1810), antiguo discípulo del abate Nollet -muy al tanto por entonces de los descubrimientos de Joseph Priestley sobre el oxígeno, el anhídrido carbónico y los otros gases- recogidas al poco en Essai sur différentes espèces d'air qu'on désigne sous le nom d'air fixe (1779). Por eso no extraña que sea Sigaud la "sabia Clío / que temple el plectro y dicte mis canciones", en una invocación deliberada que no olvida el recuerdo del busto del maestro parisino emplazado en el gabinete del aristócrata madrileño:

¡Ven tú, Sigaud!, ¡ven tú, maestro mío!, y pues con tus ejemplos y lecciones

18 Antonio Prieto, "Del ritual introductorio en la épica culta", en Estudios de literatura europea, Narcea, Madrid, 1975, pp. 15-72.

19 "La proposición -escribe Luzín en la Poética- es la primera de las partes de cantidad con que se da principio al poema y debe contener, en general, breve y claramente, la materia o asunto del poema, el héroe principal y la deidad $\mathrm{u}$ deidades que tienen mayor parte en la acción” (p. 600). Con poca diferencia lo prescribe también S. Díez González, op. cit., pp. 58-60.

${ }^{20} \mathrm{~J}$. de Viera y Clavijo, Memorias que con relación a su vida..., p. Ixviii. 
me enseñaste a volar tal vez con brío por estos nuevos aires y regiones, tú solo debes ser la sabia Clío que temple el plectro y dicte mis canciones, para que pueda con cincel robusto esculpirlas mi amor bajo tu busto ${ }^{21}$.

El "viejo pelucón Sigaud" -con esa familiaridad afectuosa lo cita Cavanilles en su correspondencia con Viera ${ }^{22}$ - reaparece en otro apóstrofe retórico en pleno relato del canto II sobre el aire inflamable: "Explícame, Sigaud, con tu voz clara: / ¿quién inventó tan bélico meteoro?" (27, c-f). Late ahí el recuerdo de los experimentos ejecutados en su gabinete de París por el profesor de matemáticas del Louis-le-Grand y demostrador de física experimental el 24 de noviembre de $1777^{23}$. Conviene recalcar que nuestro abate invoca a una musa peculiar y extravagante -conocida, viviente y de su misma edad y sexo-, tal vez en la línea de velado trasfondo humorístico que subyace tras la aparente seriedad compositiva de Los aires fijos.

$\mathrm{Al}$ iniciar la narración de algún asunto relevante que excitase particularmente el ánimo de los oyentes, el canon de la épica culta aconsejaba que el poeta renovase la solicitud de auxilio a la musa para que le amparase o diese crédito en lo que se disponía a cantar24. "No sólo en el principio del poema tiene lugar la invocación”, subraya Luzán. "Los poetas suelen usarla en otras muchas partes del poema, siempre que se ofrece haber de referir alguna cosa muy extraordinaria o muy oculta” (Poética, p. 603). Así, en un momento de especial trascendencia del canto XI de Les mois (1779), Roucher se siente cansado y suplica su ayuda: "Muse, viens ranimer mes esprits épuisés! / Viens, et que mes pinceax, plus fiers et plus terribles, / réproduisent le Nord dans ses beautés horribles!"25. Lo propio hará Viera cuando, ya asentado en Madrid,

${ }^{21}$ J. De Viera y Clavijo, Los aires fijos, ed. José Cebrián, P. Lang, Bern-BerlinFrankfurt, 1997, I, 2. Cito por canto, número de estrofa y, en su caso, versos.

${ }^{22}$ José Cavanilles, Cartas a José Viera y Clavijo, ed. Alejandro Cioranescu, Aula de Cultura, Santa Cruz, 1981, p. 32.

${ }^{23}$ José de Viera y Clavijo, Apuntes del diario e itinerario de mi viage a Francia y Flandes, Imprenta Isleña, Santa Cruz, 1849, p. 85.

${ }^{24}$ Pueden verse numerosos ejemplos de este tópico tradicional de la épica en mi libro El mito de Adonis en la poesía de la Edad de Oro, P.P.U., Barcelona, 1988, pp. 103-107.

${ }^{25}$ Les mois, poème en douze chants, Quillau, Paris, 1779, t. 2, p. 276. 
redacta el canto añadido de La máquina aerostática (1783), sexto y último de Los aires fijos. Precisa ahora de nuevos bríos poéticos para cantar el prodigioso invento que inmortalizó a Montgolfier, "el primero / que emulando de Arquitas la paloma, / del vapor más sutil y más ligero/ llenaste un vasto globo y gran redoma" (87, a-d):

Nuevo prodigio el ánimo arrebata.

¡Vuelve, musa, a inspirarme!, y la voz mía

más firme cantará la invención grata

con que el mortal por colmo de osadía,

desdeñando la tierra vuela y trata

de acometer la etérea monarquía,

donde hasta aquí reinaba sola Juno,

fiera de ser más libre que Neptuno (85).

Otra peculiar musa inspiradora de Viera es Karl von Linnæus (1707-1778), "ilustre inventor del ingenioso sistema sexual de las plantas", cuya taxonomía y nomenclatura había ido imponiéndose poco a poco en España a partir de la Explicación de la filosofía y fundamentos botánicos de Linneo (1778) de Palau y Verdera y del Curso elemental de botánica (1785) compartido con Gómez Orte$\mathrm{ga}^{26}$. Cabe recordar que ya Voltaire había exaltado la filosofía de Newton en la famosa Épître à Mme. du Châtelet (1736), donde brinda los ingredientes retóricos necesarios para componer epístolas sobre temas científicos ${ }^{27}$. También Chênedollé -por los mismos años que nuestro poeta-, exalta en los rítmicos versos de la oda Le génie de Buffon (1795), en clave de himno epicédico, los saberes vulcanológicos del gran naturalista: "Salut, divin Buffon!, noble fils d'Uranie! / Accepte mon hommage, ô moderne Platon, / toi, dont le poétique et sublime génie / sut prêter tant d'éclat au compas de Newton!"28. Nuestro didacta, hombre pausado y metódico, no se inflama en su vejez con tanto aspaviento retórico y sensista. Su "suave" lira, en cambio, aspira a cantar con el auxilio de quien "la botánica ya adora / por numen fiel", el "inmortal Linneo", los desposorios de la "amable Flora" en el poemita de Las bodas de las plantas:

${ }^{26}$ Véase A. González Bueno y F. J. Puerto Sarmiento, "Ciencia y farmacia durante la Ilustración”, en Carlos III y la ciencia de la Ilustración, eds. M. Sellés, J. L. Peset y A. Lafuente, Alianza, Madrid, 1988, en esp. pp. 128-133.

${ }^{27}$ C. A. Fusil, La poésie scientifique de 1750 à nous jours. Son élaboration, sa constitution, Scientifica, Paris, 1918, pp. 38-46.

28 Charles Chênedollé, Études poétiques, H. Nicolle, Paris, 1820, p. 108. 
Los desposorios de la amable Flora cantar en un vergel es mi deseo: templa su voz mi lira y suave implora para el epitalamio no a Himeneo, sino al que la botánica ya adora por numen fiel, al inmortal Linneo: al primero que vio en las plantas todas los sexos, los amores y las bodas (ed. cit., p. 12).

La obra responde a la última etapa de la vida de Viera en el tranquilo acomodo de su arcedianato de Fuerteventura en la catedral de Las Palmas. En un principio teme encontrarse "como un viviente singular o como aquel mamey de Daute respecto a los demás árboles del contorno" 29 , pero pronto se adapta al nuevo ambiente de las islas. Hasta el punto que precisamente en esos años intensifica su labor pedagógica. Su actividad intelectual se reparte entre la Real Sociedad Económica de Las Palmas -de cuyas actas elabora un esmerado y útil Extracto (1777-1791) ${ }^{30}$-, la labor continuada en el cabildo de la Catedral -donde reordena los estatutos, condensa en varios cuadernos las Actas (1514-1791), organiza los papeles del archivo y dirige el nuevo colegio de San Marcial- el cargo de revisor de los libros extranjeros llegados a la aduana de Gran Canaria (1793) y, desde luego, en la observación y estudio científico de la naturaleza insular, de las lavas volcánicas, conchas marinas, mamíferos, aves, insectos, árboles, plantas, yerbas, etc., saberes que recoge y sistematiza en el Diccionario de historia natural de las islas Canarias (1810) ${ }^{31}$.

No es infrecuente que el poeta didáctico del siglo XvIII respalde, o por mejor decirlo, subordine su exaltación propagandística de sabios e inventores, es decir, de quienes hacen progresar a la humanidad, a una invocación retórica a Dios en el amplio crédito deísta de Ser Supremo, origen y causa del universo. Por ejemplo, Saint-Lambert subraya en Les saisons el papel fundamental de la radiación solar en la naturaleza -que prodiga "grâce et beauté" a la primavera o el "trésor des moissons" en el estío-, pero no olvi-

${ }^{29}$ Carta al Marqués de Villanueva del Prado (Canaria, 18 de enero de 1785), en Cartas familiares escritas por don José Viera y Clavijo, Imprenta Isleña, Santa Cruz, 1849, p. 44.

${ }^{30}$ Extracto de las actas de la Real Sociedad Económica de los Amigos del País de Las Palmas (1777-1790), ed. Joaquín Blanco Montesdeoca, Real Sociedad, Las Palmas, 1981.

31 Manuel Alvar, "El Diccionario de historia natural de don José de Viera y Clavijo", ed. cit. supra, n. 6, pp. xi-xxxvi. 
da concederle a la voluntad creadora del Esprit Universel la suprema condición de "arbitre des destins" y "maître des éléments": "Esprit Universel que l'homme ose implorer, / accepte mon hommage et daigne m'inspirer" (ed. cit., p. 40). Nuestro avisado abate declara también en el exordio de Los aires fijos que el Padre Omnipotente -ordenador de "este vario espectáculo del mundo"se digna franquear de vez en cuando "a algún ingenio en discurrir fecundo / ciertas llaves maestras" necesarias para poder acceder a nuevos inventos y descubrimientos como el barómetro de cubeta de Torricelli, la descomposición de la luz blanca mediante el prisma óptico de Newton o el más reciente del pararrayos (1752) por Benjamin Franklin (1706-1790):

Si Él hizo a Torricelli que pesase en tubo estrecho el mar de la atmosfera, que Newton con un prisma disecase los siete rayos de la luz primera; que Franklin con su barra le robase el rayo a Jove, el éter a la esfera, también guió a Priestley cuando le dijo: "Toma esta tierra, saca el aire fijo" (I, 4).

El encomio de estos personajes de la ciencia, elevados al pedestal solemne de los héroes de la épica culta, es una novedad de la poesía didascálica del siglo ilustrado. Y aún más cuando todavía viven -como en el caso de Franklin- o pertenecen a la misma generación del poeta, como Priestley o Sigaud de Lafond. No hay duda de que Viera sintió una devota admiración por el "célebre americano", figura muy popular y familiar en la sociedad francesa entre 1776 y $1785^{32}$. Lo vio por vez primera en la junta de la Académie des Sciences de París del 12 de noviembre de 177733 . Y meses más tarde, en enero de 1778, en la de Medicina, donde el científico y diplomático estadounidense fue recibido y despedido "con aplausos y palmoteos" (ibid., p. 97). Pero no llegó a conocer al "héroe de los estados angloamericanos" -así lo llama en las Memorias (p. lxvii) - hasta pocos días antes de su marcha definitiva de la ciudad del Sena, en la última visita girada a la tertulia de La Blancherie $^{34}$. No obstante, el teatral encuentro de Franklin y Voltaire

32 David Schoendurn, Triumph in Paris: The exploits of Benjamin Franklin, Harper, New York, 1976.

${ }^{33}$ J. De Viera y Clavijo, Apuntes del diario e itinerario..., p. 82.

${ }^{34}$ Ibid., p. 117. Sobre el salón y la aventura editorial de La Blancherie, véase Hervé GuÉnot, “C.M. Pahin de La Blancherie et la Correspondance générale pour 
en el Louvre, en la asamblea de la Académie des Sciences del 29 de abril, fue, acaso, la anécdota más recordada en detalle por Viera. La masiva afluencia de gente le hizo llegar a duras penas a la sala de juntas y hubo de sentarse en el suelo -a los pies de D'Alembert, en su caso- durante la solemne y larga sesión, "como lo hicieron muchas personas distinguidas sin exceptuar a algunos ministros extranjeros":

Cuando entró el referido Voltaire, se hubo de hundir la sala a aplausos y palmoteos del concurso. Hallábase allí el célebre filósofo Franklin, el libertador de la América inglesa su patria, el cual, adelantándose a recibir al filósofo francés, ambos se besaron y abrazaron con nuevos aplausos del concurso ${ }^{35}$. Voltaire, viejo, flaco, arrugado, octogenario, llevaba una casaca de terciopelo negro de corte antiguo, chupa hasta las rodillas de una tela color de rosa con ramos de plata, medias de embotar, vueltas de encajes en la camisa que le cubrían casi todos los dedos de la mano, pelucón de tres nudos y su muleta. Franklin tenía un vestido entero de paño color de buey, con medias iguales, gran corbata, su pelo propio entrecano por detrás de la oreja, que no le llegaba a la espalda, una calva muy reverenda y sus espejuelos de gafas. Era un hombre como de setenta años, un poco lleno, blanco y de buen color ${ }^{36}$.

Fue en ese 1778 de renombradas aclamaciones cuando Houdon labró el busto en mármol blanco de Franklin, al que Turgot añadió en un epigrama latino la divisa que lo inmortalizaría: Eripuit

les sciences et les arts (1779-1788)", LVe Congrès de l'Association Bourguignone des socié-

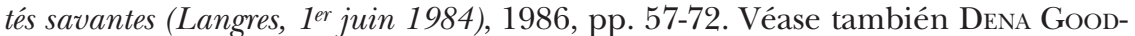
MAN, The Republic of Letters. A cultural history of the French Enlightenment, Cornell University, Ithaca-London, 1994, pp. 242-253.

${ }^{35}$ La anécdota la recoge también John Adams (1735-1826) en su Diary, algunos años más tarde presidente de los Estados Unidos de Norteamérica (1797): "Neither of our philosophers seemed to divine what was whised or expected; they however took each other by the hand, but this was not enough. The clamour continued until the explanation came out: Il faut s'embrasser à la françoise! The two aged actors upon this great theatre of philosophy and frivolity then embraced each other by hugging one another in their arms and kissing each other's cheeks, and then the tumult subsided. And the cry immediately spread through the whole kingsdom, and I suppose over all Europe: Qu'il étoit charmant. Oh! Il étoit enchantant de voir Solon et Sophocles embrassans! How charming it was! $\mathrm{Oh}$, it was enchanting to see Solon and Sophocles embracing!", Diary and autobiography of John Adams, ed. L. H. Butterfield, Harvard University, Cambridge, 1961, t. 2, p. 307.

36 Apuntes del diario e itinerario..., p. 115. 
calo fulmen sceptrumque tyrannis, en indirecta pero patente alusión al rey Jorge III de Inglaterra ${ }^{37}$. Nuestro abate debió de sentirse atraído por el sincretismo aforístico del verso, ya que lo tradujo en una cuarteta de romance que se conserva entre sus autógrafos poéticos: una prueba más de su admirado aprecio por el renombrado polígrafo estadounidense ${ }^{38}$.

La evocación nostálgica y emocionada de Franklin, "nuevo Prometeo / que con la más dichosa estratagema / al cielo le robaste el fuego puro", reaparece en Las cometas (1811), poemita de senectud en romance endecasílabo dedicado a los niños. Es, probablemente, la última producción literaria salida de la pluma de nuestro anciano abate, quien se ocultó en un estrambótico pseudónimo -Anacleto Cambreleng Leal y Gaviria- cuando lo dio a la estampa en 1812. "Poema heroico en un canto", a la luz del metro y de la breve extensión. Pero la intencionalidad didáctica del anciano abate, amable y tolerante con la infancia, a la que ha dedicado buena parte de sus últimos años, se prodiga a lo largo de los versos en explicaciones sobre las cometas de los niños, "sin que sea de mi lira el grato asunto / aquellos melancólicos cometas / con que en los cielos, muy de tarde en tarde, / algunos angelitos tal vez juegan" 39 . Con el recuerdo del famoso experimento sobre la electricidad atmosférica llevado a cabo por Franklin en junio de 1752 por medio de una cometa ${ }^{40}$-relatado en pormenor por Priestley en The history and present state of electricity (1767) ${ }^{41}$ - Viera ensalza el invento del pararrayos y, en esa línea, el papel desempeñado por el modesto juguete infantil en tan "audaz e ilustre empresa":

37 Carl van Doren, Benjamin Franklin, Penguin, New York, 1991, p. 606.

38 "Ved el águila intrépida / de los americanos, / que arrancó el rayo a Júpiter / y el cetro a los tiranos", Colección de algunos opúsculos poéticos de D. J. V. C., Biblioteca Municipal de Santa Cruz de Tenerife, s.a., ms. 22.

${ }^{39}$ Las cometas. Poema heroico en un canto. Lo saca a la luz, recogiéndolo de su memoria, D. Anacleto Cambreleng Leal y Gaviria, Imprenta de la Real Sociedad, Gran Canaria, 1812, p. 1.

40 Véase I. Bernard Cohen, Benjamin Franklin's experiments: A new edition of Franklin's "Experiments and observations on electricity", Harvard University, Cambridge, 1941. En breve, y del mismo autor, "The science of Benjamin Franklin", en Critical essays on Benjamin Franklin, ed. M. H. Buxbaum, Hall, Boston, 1987, en esp. pp. 131-135.

${ }^{41}$ J. Dodsley, London, pp. 179-181. El suceso lo trae también el divertido libro de P. M. ZALL, Ben Franklin laughing. Anecdotes from original sources by and about Benjamin Franklin, University of California, Berkeley, 1980, pp. 74-75. 
Un filósofo, al ver que los nublados que tronan tanto y que relampaguean, son de electricidad grandes meteoros, dotados de energía, horror y fuerza, dijo: "yo soy capaz de despojarlos de esta virtud...". Le pide su cometa a un bravo joven; se la da, y al punto quita el papel, afórrala de seda; en la vara del medio pone fijo un grueso alambre, que por la cabeza se extiende un palmo y que termina en punta; en lugar del cordel ata una cuerda de aquellas que el violín usa en sus bajos por estar de metal toda cubierta; en un cordón de seda ésta remata, con la cual la cometa se maneja, para dejarla aislada y sólo pase por el metal la eléctrica centella.

Preparada la máquina insidiosa, no tardó en presentarse una tormenta con tempestuosas nubes, y en su busca la cometa subió... ; cosa estupenda! Por el cordel metálico bajaron al instante las chispas, con sorpresa de cuantos observaron un prodigio que el ingenio del hombre recomienda.

¡Tú, Franklin, fuiste el nuevo Prometeo que con la más dichosa estratagema al cielo le robaste el fuego puro! ¡Tú le arrancaste de su airada diestra a Júpiter el rayo, y enseñaste el arte de impedir que nos ofendan! ${ }^{42}$.

Pero el "nuevo Plinio" de los cuatro primeros cantos de Los aires fijos es, por antonomasia, Joseph Priestley (1733-1804) ${ }^{43}$. Su epopeya científica la describe Viera en sobrios y neoclásicos versos, a veces con cierta guasa conceptista. Nos lo presenta abstraído, absorto en su gabinete experimental, a un "solo paso" de culminar el hallazgo del "cuerpo sutil" o gas que "cien veces se escapó de sus

42 Las cometas, pp. 5-6. Nuestro vate recrea en estos versos el lance señalado en The history and present state of electricity (1767) de Priestley, leído sin duda en el texto de la traducción francesa (Hérisant le Fils, Paris, 1771, 3 ts.).

43 T. E. Thorpe, Joseph Priestley, Dent/Dutton, London-New York, 1906, pp. 167-223. 
umbrales / burlando los conatos que pusieron" en conseguirlo sus predecesores Van Helmont, Boyle, Black y Hales. Las representaciones alegóricas, abundantes en la épica culta ${ }^{44}$, asumen en el poema el papel de los dioses de la epopeya antigua, cuyos designios prevalecen sobre los de los mortales. Así, Naturaleza siente tan "vil atraso" y encomienda a la Física y a la Química que enseñen a Priestley la vía más rápida de obtener aire fijo, precipitando aceite de vitriolo rebajado sobre piedra caliza:

"Muéstrate audaz y un baño te procura con una plancha y un embudo en ella; pon trastornado un frasco de agua pura, y en otro vaso de estructura bella, donde un tortuoso tubo se asegura que de la cera mole se resella, echa polvo calizo y en él sólo disuelto en agua aceite de vitriolo".

Así lo ejecutó, mas al instante que el ácido rompió la tierra bruta creyeras ver al Eolo triunfante cuando suelta los vientos de su gruta: la mole de agua impelen por delante con el silbo y hervor de la disputa, cual Aquilón de ráfagas inquietas, los mefitis, los dampas y mofetas (I, 8-9).

Nuestro abate recuerda ahí el pasaje de la Eneida (I, pp. 52-101) en que Virgilio describe la atropellada y furiosa salida de los Vientos de la cueva de Eolo, por medio de una perífrasis metafórica, que enaltece y eleva en epicidad las violentas "ráfagas inquietas" que genera la acción del ácido sobre la "tierra bruta", o sea, el polvo de caliza, en el tubo de ensayo ${ }^{45}$.

44 Todavía a fines de la centuria admite DíEz González en Instituciones poéticas que el vate tiene la facultad de "invocar la asistencia de aquellas singulares virtudes que tengan conexión con la materia del poema, expresándolas por su nombre y, en cierto modo, personalizándolas" (p. 62).

${ }^{45}$ Los versos transmiten en imaginada alegoría los apuntes tomados por nuestro abate el 17 de noviembre de 1777, en su primer día de asistencia al curso sobre gases o aires fijos de Sigaud de Lafond: "Ante todas cosas nos hizo la historia de estos fluidos aeriformes, trayéndola desde Van Helmont, Boyle, Hales, hasta el célebre Priestley. Explicó el uso de los vasos y máquinas para recogerlos y manejarlos con las mejoras de su propia invención. Luego procedió a extraer el aire fijo en esta forma: en un pequeño frasco de cristal echó una corta porción de creta o tierra caliza pulverizada, y encima una medida de tres partes 
Priestley, inspirado "del genio que le guía", obtiene luego aire inflamable-hidrógeno- por el método de la efusión de aceite de vitriolo rebajado sobre limadura férrica, ensayado y descrito por Cavendish en Three papers containing experiments on factious air (1766). Pero Viera transmite en Los aires fijos el concepto vago e inconcreto de aire inflamable -ora referido al hidrógeno, ora a otros gases hidrogenados como el metano de los pantanos o el firedamp de las minas- que tras sus primeros experimentos expuso el químico inglés y divulgó en sus disertaciones didascálicas Sigaud de Lafond (ibid., p. 85):

La lucha del metal hijo de Marte, calienta el vaso con furor interno, y el olor triste anuncia en toda parte un aire, aborto de abreviado Averno; por entre el agua le aprisiona el arte sin que le valga ser sutil y tierno, que el hombre, que en la tierra ha dominado, tiene en los aires nuevo principado (II, 23).

El "mejor descubrimiento" realizado luego por Priestley no es otro que el del aire nitroso o dióxido de nitrógeno (1772), explicado en detalle en la primera sección de Experiments and observations on different kinds of air (1774). Pero el espíritu burlón y amante de los equívocos del poeta nos lo presenta antes coronado por la Química con una alegórica guirnalda "de vivo resplandor y mariposas" tras tanto fogonazo de laboratorio. Naturaleza lo anima y siembra el camino de "frescas rosas", preludio de venturosos y prometedores triunfos (II, 36). El hallazgo acaece "apenas el crepúsculo rayaba / con el más puro y diáfano reflejo”. Así, en las primeras luces del amanecer, al teñirse el aire del color rosáceo de la Aurora y enviar su "rubia luz" al Támesis "como a la mansa luna de un espejo", nuestro sabio vierte agua fuerte sobre las "marciales limaduras", pero la acalorada efervescencia originada -"el hervor y tropelía / de aquella Estigia”- lo arredra y hace que mude la ralladura metálica por un trozo de azúcar. En realidad, Viera narra en los versos los dos procedimientos usados por Sigaud de Lafond

de ácido vitriólico y cinco de agua. Suscitada al instante la efervescencia, subió en gruesas y continuas ampollas un aire claro que, caminando por un tubo de vidrio retorcido, iba a dar a una pequeña tina llena de agua, donde encontrando otro frasco también de agua, vuelto boca abajo, la iba desalojando y ocupando su lugar", Apuntes del diario e itinerario..., pp. 82-83. 
para obtener aire nitroso ante la concurrencia del día 21 de noviembre de 1777, así como las propiedades del gas allí elucidadas ${ }^{46}$ :

El matrás con el fuego y por el tubo

empezó a vomitar un aire claro

que subiendo en ampollas por el cubo

se fue a alojar al recipiente avaro;

aire inocente fue mientras estuvo

sin mezcla del común, pero reparo

que uniéndose a él, al mismo instante

huele, se turba y pone rutilante (III, 39).

Por último, el canto IV describe la obtención y propiedades del aire desflogisticado u oxígeno -el "más sano y salutífero para respirar los vivientes"-, extraído por Priestley el 1 de agosto de 1774 por medio de reducción de mercurius calcinatus per se, o sea, óxido de mercurio, y "precipitado rojo", originado por el calentamiento del nitrato mercúrico hasta convertirse en el mismo óxido, y dilucidado en el segundo tomo de Experiments and observations on different kinds of air (1775) ${ }^{47}$, dedicado a Pringle. "Hijo así de la Aurora y de Mercurio -apostilla Viera en los versos- / este aire debe su inmortal nobleza / a no tener ningún principio espurio, / ningún flogisto o causa de impureza". En consecuencia, nuestro abate recoge, apoya y difunde en España la quimera diversificada del flogisto, materia ígnea "que en los cuerpos ocasiona adusto / color, olor, inflamación y gusto", sostenida por Stahl, Black, Cavendish, Priestley y otros químicos y desmontada por Lavoisier en Réflexions sur le phlogistique (1785). Nuestro perspicaz didacta encomia las virtudes del oxígeno, "cuatro veces más puro y sin las heces / de los aires comunes generales", superior en calidad al aire de las cumbres del Olimpo y del Parnaso y más sutil que el que "en Edén sopló al ocaso". Y gusta subrayar con su experiencia el justo placer que le produjo contemplar su logro. Experimento que, una vez

46 "Luego -recalca nuestro viajero- procedió a extraer el aire nitroso y lo sacó de dos maneras: primera echando sobre limaduras de hierro en un frasco una poca de agua fuerte o ácido nitroso; pero como esta unión suscitaba una efervescencia demasiado viva y tumultuosa, con vapores rojos y calor, mudó de método y extrajo el dicho gas poniendo sobre fuego lento un matraz de vidrio con ácido nitroso y azúcar, de cuya mezcla se levantaron muchas campanitas de aire transparente, que se recogían en la máquina químico-hidráulica, de que ya di una idea. Este aire nitroso se conserva muy bien diáfano mientras no se mezcla con el atmosférico; pero así que se mezcla se pone rubicundo y caliente y exhala un fuerte olor de espíritu de nitro", Apuntes del diario e itinerario..., p. 84.

${ }^{47}$ J. Johnson, London, pp. 34-40. 
más, observó por vez primera en París de manos de Sigaud de Lafond el 26 de noviembre de 1777:

Puso en un matracito de vidrio una corta porción de polvos de precipitado rojo o de Juanes, que son hechos de azogue calcinado, y colocándolos sobre el fuego vivo de un braserillo de carbón, fue recogiendo por medio del aparato ya insinuado un aire tan particular que la luz de una vela al entrar en él adquiría un resplandor y brillantez que deslumbraba la vista; una mecha recién apagada se encendía dando un estampido; el aire nitroso absorbía grandes porciones de él; mezclado con el inflamable ocasionaba un increíble estrépito; los animales metidos en él vivían cuatro tantos más que en el aire común ${ }^{48}$.

Con el recurso didáctico de las anotaciones eruditas, Edmund Burke (1729-1797), autor de unas exitosas Reflections on the Revolution in France (1790), canta también en los exaltados versos pareados de Heroic epistle to Joseph Priestley (1791) las virtudes morales del descubridor de los nuevos gases y "natural philosopher" de Leeds, a quien llama con admirada reverencia "great doctor" y "prince of the philosophers, whose splendid page / obscurs the glories of each former age": "In England, Priestley, never hope to find / a philosophic apathy of mind. / For in this isle we few but madmen see, / while sober reason only dwells with thee!" 49 . Priestley entrega su cetro de héroe épico de los adelantamientos de la ciencia, de paladín de los nuevos saberes aerológicos del Siglo de las Luces, al médico Jan Ingenhousz (1730-1799), protagonista del canto $\mathrm{V}$ de Los aires fijos, añadido por nuestro abate en 1781 tras su regreso a Madrid del viaje a Italia y Alemania y, en concreto, de su estadía de "cinco meses cabales" en la Viena del emperador José II. Viera lo conoció en persona y asistió varias veces a las demostraciones de física y química que ofrecía en su casa sobre electricidad y "aires de las plantas" 0 . Recuerda, por ejemplo, que el 12 de diciembre de 1780 le regaló "dos disertaciones suyas en inglés, leídas a la Real Sociedad de Londres, sobre las propiedades del electróforo y otros fenómenos eléctricos"51. Cabe señalar que el

48 Apuntes del diario e itinerario..., pp. 85-86.

${ }^{49} \mathrm{~J}$. Robinson, London, p. 29.

50 José Cebrián, "Del epistolario de Viera y Clavijo y sus amigos de Viena”, en El siglo que llaman ilustrado. Homenaje a Francisco Aguilar Piñal, eds. J. Álvarez Barrientos y J. Checa Beltrán, CSIC, Madrid, 1996, pp. 209-220.

${ }^{51}$ José De Viera y Clavijo, Extracto de los apuntes del diario de mi viaje a Italia y Alemania, Imprenta Isleña, Santa Cruz, 1849, parte segunda, p. 14. 
sabio holandés -médico de cámara de la familia imperial desde 1768- había regresado poco antes a Inglaterra, donde recibió el nombramiento de fellow de la Royal Society y el mecenazgo de lord Shelburne, hasta entonces protector de Priestley. Sus Experiments upon vegetables (1779) aportaban por vez primera una novedosa y sistemática exposición sobre el influjo de la luz solar en la producción de oxígeno por parte de la materia verde de las plantas ${ }^{52}$. Viera abre el canto $\mathrm{V}$ sobre los aires vegetales con una breve referencia enaltecedora a los "triunfos, palmas, preeminencias" de Priestley, singularizados en la entrega de la prestigiosa medalla Copley en el anniversary meeting de la Royal Society (1773) ${ }^{53}$-Franklin lo había recomendado varias veces antes sin éxito ${ }^{54}-$, y en el discurso honorífico pronunciado en el solemne acto protocolario por sir John Pringle:

El regio alcázar que a la docta Urania sobre sólidas bases de experiencias la Sociedad de Albión contra la insania erigió para solio de las Ciencias, abrió sus puertas y la Gran Britania vio que los triunfos, palmas, preeminencias buscaban a Priestley como blasones dignos de sus trabajos e invenciones.

Pringle, amado de Apolo y de Minerva, perorando cual sabio presidente, le dijo al fin, atenta la caterva:

"Tú has demostrado al hombre claramente que la más suave o más nociva yerba, que el árbol más humilde o eminente, con los aires que absorben y que fluyen a la salud del orbe contribuyen" (V, 65-66).

Nuestro poeta estriba el canto V en la remembranza de los "curiosos experimentos" ejecutados por Ingenhousz en su casa de Viena, pero, sobre todo, en el atento repaso del contenido de Experiments upon vegetables. Leyó sin duda la obra de Ingenhousz a través de la versión francesa, adquirida, como tantas otras, por el Marqués de

52 Howard Reed, "Jan Ingenhousz, plant physiologist, with a history of the discovery of photosynthesis", Chronica Botanica, 11 (1949), 285-396.

53 Douglas McKie, "Joseph Priestley and the Copley medal", Ambix, 9 (1961), 1-22.

${ }^{54}$ Robert E. Schofield, A scientific autobiography of Joseph Priestley (1733-1804), MIT, Cambridge, MA, 1966, pp. 61-63. 
Santa Cruz -y destinada a su gabinete de física experimental- en el segundo viaje por las cortes europeas ${ }^{55}$.

Viera recuerda en sus alusiones didascálicas la inoculación del virus de la viruela practicada por Ingenhousz en 1768 a la familia imperial austríaca, "salva por su acierto / de la fatal variólica epidemia", enfermedad muy común por entonces y causa de numerosas bajas en la población de toda Europa ${ }^{56}$. Como ya vimos con Sigaud de Lafond, estamos otra vez ante el encumbramiento poético en clave neoclásica de un héroe coetáneo de la ciencia a quien el poeta tuvo ocasión de conocer y tratar. Perteneciente, además, a su misma generación cronológica.

Que su poesía enaltecedora de la ciencia no iba a pasar a los manuales de literatura e iba a ser ingrata a los recolectores de bellezas lo sabía Viera de antemano. Vale por completo para todos sus cantos épicos lo que ya advirtió en 1766 -sigue hoy vigente, desde luego- sobre el primero de ellos:

el poema de Los vasconautas es un juguete, una urbanidad, un puro esparcimiento del ánimo, trabajado con precipitación, y como una pieza fugitiva que ya no se leerá el año que viene. En esta suposición, vengan Aristarcos, vengan Zoilos; pero tú, amigo lector, si conoces el mundo, no la defenderás sino delante de los discretos o de los amigos. Los demás no entienden de razones ${ }^{57}$.

Los nombres de Fontenelle, Torricelli, Newton, Boyle, van Helmont, Black, Hales, Canton, Nollet, Volta, Chaulnes, Herschel o los Montgolfier alternan en Los aires fijos con personajes alegóricos como Naturaleza, la Física, la Química o la Posteridad. Júpiter, Eolo, Mercurio, Pomona o Faetonte se codean con el padre Lana, con Arlandes o con Pilâtre de Rozier en una atemperada simbiosis de las leyendas de la tradición clásica, los recientes paladines de la ciencia empírica y los primeros tripulantes de globos aerostáticos, aplicación utilitaria, de popular resonancia, de la nueva física neumática a las eternas ansias humanas de surcar y dominar los aires.

55 Expériences sur les végétaux, spécialement sur la propriété qu'ils possèdent à un haut degré soit d'améliorer l'air quand ils sont au soleil, soit de le corrompre la nuit ou lorsqu'ils sont àl'ombre, Didot le Jeune, Paris, 1780.

${ }^{56}$ JoAQuín ARCE, "Scienza e lirica illuministica: dall'inoculazione al vaccino in Italia e in Spagna”, en Letteratura e scienza nella storia della cultura italiana. Atti del IX Congresso dell'Associazione Internazionale per gli Studi di Lingua e Letteratura Italiana, Manfredi, Palermo, 1979, pp. 598-609.

${ }^{57}$ Discurso de la poesía épica antepuesto a Los vasconautas, p. 20. 
José de Viera y Clavijo creyó sin duda que los saberes adquiridos en los cursos de Sigaud de Lafond, Sage y Valmont de Bomare, en el ensayo personal de los experimentos químicos y en la lectura de Linneo, Macquer, Brisson o Ingenhousz, podían transmitirse también en el agradable envoltorio de la poesía didáctica. La "afable musa" didascálica, "sans masque, sans cothurne et sans illusion" -en el decir de Delille- no podía permanecer ajena o insensible ante el asombro generado por los adelantamientos científicos y ante la rápida e imparable transformación del mundo ${ }^{58}$. Por eso escribió nuestro sabio abate Los aires fijos (1780-1784), Las bodas de las plantas (1806) e, incluso, Las cometas (1811). Sigaud de Lafond, Priestley, Ingenhousz, los Montgolfier, Linneo y Franklin hubieron de ser sus héroes. La ciencia española del siglo xviII era incapaz de brindar al poeta didáctico algo semejante. Incluso remotamente.

José Cebrián Harvard University

58 JohQuín Arce, La poesía del siglo ilustrado, Alhambra, Madrid, 1981, pp. 292-314. 